\title{
Recovery of Salmonella isolated from eggs and the commercial layer farms
}

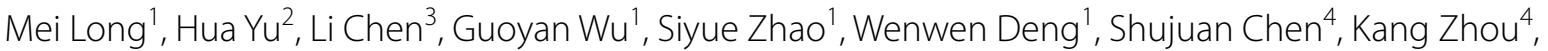 \\ Shuliang $\mathrm{Liu}^{4}$, $\mathrm{Li} \mathrm{He}^{4}$, Xiaoling Ao${ }^{4}$, Yubao Yan², Menggen Ma', Hongning Wang ${ }^{4}$, Margaret A. Davis ${ }^{5}$, \\ Lisa Jones ${ }^{5}$, Bei Li ${ }^{7}$, Anyun Zhang ${ }^{5,6^{*}}$ and Likou Zou ${ }^{1 *}$
}

\begin{abstract}
Background: Salmonella is recognized as a common bacterial cause of foodborne diarrheal illness worldwide, and animal or its food products have been the most common vehicles of the Salmonella infections. This study aimed to investigate the distribution of Salmonella in two commercial layer farms and to determine the genetic relatedness between these strains. The Salmonella isolates were serotyped by slide agglutination using commercial antisera and analyzed for genetic relatedness using pulsed-field gel electrophoresis (PFGE).

Results: The internal environment had the highest prevalence of Salmonella (14/15, 93.3\%), followed by external environment $(60 / 96,62.5 \%)$ and egg samples $(23 / 84,27.3 \%)$. The prevalence of Salmonella in the environment was significantly higher than that in egg samples $(p<0.05)$. The occurrence of Salmonella in the internal environment (93.3\%) was relatively higher than in the external environment (55.6-77.2\%). The 111 isolates were distributed among 15 PFGE types, and the PFGE results suggested that there existed cross-contamination between these strains not only from eggs, but also from the environments.
\end{abstract}

Conclusions: The findings indicated ongoing Salmonella cross-contamination inside or outside of the layer farms, and that Salmonella could also spread along the egg production line.

Keywords: Salmonella, Environment, Eggs, Production chain, Layer farm

\section{Background}

Salmonella enterica is recognized as one of the most common bacterial cause of human diarrheal illness worldwide, which has been a considerable burden to public health and economic loss. There are 1.4 million occurrences of human salmonellosis in the USA annually, 95\% of which were foodborne [1]. Accordingly, Salmonella-related infections have been associated with $\$ 365$ million in annual direct medical costs [2]. In the European Union, 99,020 food-borne cases caused by Salmonella were reported in 2010 [3]. The estimated incidence of Salmonella gastroenteritis in East Asia circa

\footnotetext{
*Correspondence: zhanganyun@scu.edu.cn; zoulikou@sicau.edu.cn ${ }^{1}$ College of Resources, Sichuan Agricultural University, Chengdu 611130, People's Republic of China

${ }^{5}$ College of Life Sciences, Sichuan University, Chengdu 610065, People's Republic of China

Full list of author information is available at the end of the article
}

2006 was 3980 cases per 100,000 person-years (compared to a global incidence of 1140 per 100,000 person-years) [4]. Salmonella outbreaks are commonly associated with consumption of contaminated food, such as poultry meat and eggs, which have been identified as the important vehicle for human salmonellosis $[5,6]$.

Salmonella has been frequently recovered from laying hen house environments, suggesting that the environment of the poultry farm can act as a reservoir for Salmonella and contribute to the horizontal dissemination of Salmonella via animal-to-animal contact and contaminated feed [7-9]. In addition to feed, the water, feces, dust, cages and litter contaminated with Salmonella are important sources of infection [9-15]. Many studies focused on the distribution of Salmonella among different sample origins in poultry environments, or on antibiotic resistance, virulence, and control strategies $[9,14,16$, 17]. However, there have been few investigations of the 
association between Salmonella isolates recovered from the internal and external poultry environment and the relationship between isolates obtained from sequential points along the production chain. Recognition of these aspects is important in controlling the spread of Salmonella and reducing the prevalence of Salmonella in production settings.

Although all serotypes may be regarded as potential human pathogens, the majority of infections are caused by a very limited number of serotypes, of which Salmonella Enteritidis and Salmonella Typhimurium are the two most common ones associated with gastrointestinal disease of humans $[18,19]$.

There have been increasing concerns over the past 30 years about the worldwide emergence of multi-drug resistant phenotypes among Salmonella serotypes, in particular S. Typhimurium. Other non-typhoidal Salmonella serovars, such as $S$. Braenderup, $S$. Derby, $S$. Jerusalem and $S$. Bovismorbificans [15, 20], have caused outbreaks but they do not frequently occur or rarely outbreaks. Several serotypes can colonize the digestive tract of chickens and be excreted in feces, which can persist in the environment and may lead to vertical and horizontal transmission in chickens, ultimately contaminating the processing chain and retail poultry products [18].

Previous studies have investigated the distribution and prevalence of Salmonella in broiler chickens and the processing environments $[9,14]$. In Guangdong Province, China, the most frequent serotypes isolated from raw retail poultry meat were $S$. Enteritidis, Salmonella Indiana and $S$. Typhimurium [21] and from live chickens, the most frequent serotypes were unidentified, followed by $S$. Typhimurium and $S$. Enteritidis [22]. However, very little is known about the distribution and relatedness of Salmonella from layer farms and the variation of that distribution along the production processing chain, particularly in China. Therefore, the objective of this study was to investigate the distribution of Salmonella at each particular link in the internal and external environments of two commercial layer farms and to analyze the relatedness of the prevalent strains along with the egg production chain.

\section{Methods}

\section{Sampling farms}

Sampling was conducted on two layer farms, one built in 1999 and the other in 2006, which both belong to the same commercial egg production company and are $5 \mathrm{~km}$ apart. The old layer farm has a capacity for 250 thousand birds, while the new layer farm can hold 500 thousand birds. Additionally, the technical characteristics of the old layer farm are different from those of the new layer farm. Due to the construction time, the facilities of the old layer farm are relatively outdated, and the new layer farm has modern farming technology with fully automated management, egg harvesting, egg washing, disinfection, ultraviolet (UV) irradiation and packaging.

\section{Egg collection}

Eighty-four egg samples were collected from three main parts of the production chain, including cages (placed at the front, middle, and posterior of the internal henhouse) of the old layer farm, egg belt (in the front, middle, and posterior of the belt) and egg collection conveyer of the new layer farm. In addition, retail eggs traced to their farm of origin were collected from the supermarket within their original packaging. All eggs were aseptically transferred into individual sterile plastic bags and transported to the laboratory for cultivation and isolation within $6 \mathrm{~h}$.

\section{Environmental sample collection}

The environmental sampling sites included all major points of the egg processing line and environments, which can be divided into two main parts, the internal and external environments. These sampling sites included disinfectant system, soil, feces, dust and gutter samples of the outdoor environment, and wet curtain cooling system, cage, egg nest samples of the indoor environment of the old layer farm. Samples from the washing room, washing water, irradiation room, package room, storage room and feces of the outdoor environment, and cage, egg belt and egg collection conveyer samples of the indoor environment were collected in the new layer farm (Tables 1 and 2). A total of 126 environmental samples were collected using a sterile cotton swab. After collection, all samples were transported to the laboratory in an ice chest and stored at a $4{ }^{\circ} \mathrm{C}$ cooler for bacterial isolation within $6 \mathrm{~h}$.

\section{Salmonella enrichment}

Modified enrichment methods were used based on the preliminary data on Salmonella growth from eggs described previously [18]. Briefly, a swab technique was used to sample intact egg surfaces. Swabs were directly inoculated into $10 \mathrm{~mL}$ Buffer Peptone Water (BPW) for pre-enrichment and incubated at $37{ }^{\circ} \mathrm{C}$ for $18-24 \mathrm{~h}$. After eggshell surface processing, each eggshell surface was dipped into 3:1 solution consisting of three parts of $70 \%$ alcohol to one part iodine tincture solution for $1 \mathrm{~min}$ to kill any bacteria on the outside of the shell and was allowed to air dry in a biosafety cabinet. The eggs were cracked open and egg contents were placed into a sterile container. The internal eggshell was washed with sterile phosphate buffered saline (PBS) to rinse off the adhering egg albumen. The internal shell and membranes from eggs were crushed into pieces, transferred to a $250 \mathrm{~mL}$ 
Table 1 The prevalence and distribution of Salmonella in the old layer farm

\begin{tabular}{|c|c|c|c|c|c|c|c|c|}
\hline \multirow[t]{2}{*}{ Origins } & \multirow[t]{2}{*}{$\mathrm{N}^{\mathrm{a}}$} & \multicolumn{6}{|c|}{ Salmonella serotypes } & \multirow[t]{2}{*}{ Prevalence $^{\mathbf{b}}$} \\
\hline & & S. Derby & S. Braenderup & S. Enteritidis & S. Jerusalem & S. Bovismorbificans & Un-identified & \\
\hline \multicolumn{9}{|c|}{ External environment of the henhouse } \\
\hline Disinfection system & 5 & 1 & & & & & & $20.0 \%(1 / 5)$ \\
\hline Soil & 15 & 5 & & 3 & 2 & & & $66.7 \%(10 / 15)$ \\
\hline Feces & 13 & 11 & & & 1 & & & $92.3 \%(12 / 13)$ \\
\hline Dust & 6 & 5 & & & & & & $83.3 \%(5 / 6)$ \\
\hline Gutter & 3 & 1 & & & & & 1 & $66.7 \%(2 / 3)$ \\
\hline \multicolumn{9}{|c|}{ Internal environment of the henhouse } \\
\hline Wet curtain cooling system & 3 & 2 & & & & 1 & & $100 \%(3 / 3)$ \\
\hline Cage & 6 & 5 & & & & & & $83.3 \%(5 / 6)$ \\
\hline Egg nest & 6 & 6 & & & & & & $100 \%(6 / 6)$ \\
\hline Total & 57 & 36 & & 3 & 3 & 1 & 1 & $77.2 \%(44 / 57)$ \\
\hline
\end{tabular}

a Sample number

b The prevalence of Salmonella was among the samples in different sampling site

Table 2 The prevalence and distribution of Salmonella in the new layer farm

\begin{tabular}{|c|c|c|c|c|c|c|c|c|}
\hline \multirow[t]{2}{*}{ Origins } & \multirow[t]{2}{*}{$\mathrm{N}^{\mathrm{a}}$} & \multicolumn{6}{|c|}{ Salmonella serotypes } & \multirow[t]{2}{*}{ Prevalence $^{\mathbf{b}}$} \\
\hline & & S. Derby & S. Braenderup & S. Enteritidis & S. Jerusalem & S. Bovismorbificans & Un-identified & \\
\hline \multicolumn{9}{|c|}{ External environment of the henhouse } \\
\hline Washing room & 12 & 1 & & & 1 & & & $16.7 \%(2 / 12)$ \\
\hline Washing water & 11 & 2 & & & 3 & 5 & 1 & $100 \%(11 / 11)$ \\
\hline Irradiation room (UV) & 1 & & & & 1 & & & $100.0 \%(1 / 1)$ \\
\hline Package room & 9 & 3 & & & & & & $33.3 \%(3 / 9)$ \\
\hline Storage room & 12 & & & & 3 & & 1 & $33.3 \%(4 / 12)$ \\
\hline Feces & 9 & 4 & & 1 & 2 & 1 & 1 & $100.0 \%(9 / 9)$ \\
\hline \multicolumn{9}{|c|}{ Internal environment of the henhouse } \\
\hline Cage & 6 & 6 & & & & & & $100 \%(6 / 6)$ \\
\hline Egg belt & 6 & 6 & & & & & & $100 \%(6 / 6)$ \\
\hline Egg collection conveyer & 3 & 1 & & & 1 & & & $66.7 \%(2 / 3)$ \\
\hline Total & 69 & 23 & & 1 & 11 & 6 & 3 & $63.8 \%(44 / 69)$ \\
\hline
\end{tabular}

a Sample number

b The prevalence of Salmonella was among the samples in different sampling site

sterile triangular flask with BPW and incubated at $37{ }^{\circ} \mathrm{C}$ for 18-24 h. Subsequently, mixed egg content was inoculated into BPW and incubated at $37^{\circ} \mathrm{C}$ for $18-24 \mathrm{~h}$. The ratio of egg shell to BPW and content sample to BPW was maintained at $1: 10$ by volume. The environmental samples were also pre-enriched in $\mathrm{BPW}$ at $35^{\circ} \mathrm{C}$ for $18-24 \mathrm{~h}$.

\section{Salmonella confirmation}

One millilitre of overnight culture was inoculated to $100 \mathrm{~mL}$ Rappaport-Vassiliadis (RV) Broth and 10-100 mL Tetrathionate Broth Base (TTB) (Beijing Land Bridge Technology Co, Ltd., Beijing, China) [23] and the inoculated broth was then incubated at $42{ }^{\circ} \mathrm{C}$ for $24 \mathrm{~h}$. A full loop of each of the enrichment RV and
TTB broth was streaked on Brilliant Green Sulfadiazine agar (BGS) and Xylose Lysine Desoxycholate (XLD) plates, and then incubated at $37{ }^{\circ} \mathrm{C}$ for another $24 \mathrm{~h}$. Presumptive Salmonella colonies from each plate were stabbed into Triple Sugar Iron agar (TSI) and urea-agar slants (Beijing Land Bridge Technology Co, Ltd., Beijing, China) [24]. After $24 \mathrm{~h}$ of incubation at $37^{\circ} \mathrm{C}$. Isolates with typical Salmonella phenotypes were confirmed by PCR. The PCR assays for identification of Salmonella were previously described [25]. A 284-bp PCR product targeting invA was amplified using primers invA139 (5'-GTGAAATTATCGCCACGTTCGGGCAA-3') and invA141 (5'-TCATCGCACCGTCAAAG GAACC-3'). Confirmed isolates were stored in TSB containing $20 \%$ 
glycerol at $-80{ }^{\circ} \mathrm{C}$ until use. The isolates were further serotyped by slide agglutination using commercial antisera purchased from SSI (Statens Serum Institute, Denmark) according to the manufacturer's instructions.

\section{Pulsed-field gel electrophoresis}

All isolates were compared using pulsed-field gel electrophoresis (PFGE) analysis according to the PulseNet protocol. The XbaI-digested DNA fragments were separated in a $1 \%$ agarose gel using a CHEF MAPPER electrophoresis system (Bio-Rad, Hercules, California, USA). The electrophoresis conditions were as previously described [26]. S. enterica serovar Braenderup H9812 was used as a marker. PFGE results were analyzed by BioNumerics software (Applied Maths, Kortrijk, Belgium), and banding patterns were compared by using Dice coefficients with a $1.5 \%$ band position tolerance.

\section{Statistical analysis}

Frequency differences among the isolates were analyzed using SPSS v.12 (SPSS Inc. 1989-2003), and the Chi square test was used to determine the significance of the differences. A p value less than 0.05 was considered statistically significant.

\section{Results}

\section{Recovery of Salmonella isolates from eggs}

A total of 23 Salmonella isolates were recovered from 84 egg samples with the prevalence of $27.3 \%$. Among these 23 Salmonella, $26.1 \%(\mathrm{n}=6)$ were isolated from eggshell surface, $43.5 \%(\mathrm{n}=10)$ from internal eggshell and $30.4 \%$ $(n=7)$ from egg content. As shown in Additional file 1: Table S1, retail egg samples had a relatively higher prevalence $(n=6,50.0 \%)$ than those from the internal environment of the new layer farm $(n=10,33.3 \%)$, followed by eggs from the internal environment of the old farm $(\mathrm{n}=7,16.7 \%)$. Totally, four serotypes were detected in 23 Salmonella isolates from egg samples. $S$. Jerusalem and $S$. Braenderup were the predominant serotype $(\mathrm{n}=6$, both $26.1 \%)$, followed by $S$. Derby ( $\mathrm{n}=5,21.7 \%)$ and $S$. Bovismorbificans ( $\mathrm{n}=1,4.3 \%$ ), respectively. Additionally, $21.7 \%(\mathrm{n}=5)$ isolates was still un-serotyped.

\section{Frequency of Salmonella isolates in layer farm environment} Totally, 88 (69.8\%) Salmonella isolates were isolated from 126 environmental samples (Tables 1 and 2). Only a slight difference in the prevalence of Salmonella was found between the old $(44 / 57,77.2 \%)$ and new $(44 / 69,63.8 \%)$ commercial layer farms $(p=0.10, p>0.05)$. Among all isolates, $68.2 \%(60 / 88)$ were recovered from external samples, while $31.8 \%(28 / 88)$ were detected in internal samples. The internal environment had the highest prevalence of Salmonella (28/30, 93.3\%), followed by external environment samples $(60 / 96,62.5 \%)$ and the egg samples $(23 / 84,27.3 \%)$. The prevalence of Salmonella in environmental samples was higher than in egg samples.

The prevalence of Salmonella recovered from the old layer farm is displayed in Table 1. $44(\mathrm{n}=57,77.2 \%)$ Salmonella isolates were recovered from the old layer farm. The incidence of Salmonella in external environment of the old layer farm was $71.4 \%$ (30/42), and 93.3\% (14/15) in internal environment. In external environmental samples, the most frequently observed Salmonella contamination was in fecal samples $(12 / 13,92.3 \%)$, followed by dust $(5 / 6,83.3 \%)$, soil $(10 / 15,66.7 \%)$ and gutter samples $(2 / 3,66.7 \%)$. The disinfection system showed the lowest frequency of Salmonella $(1 / 5,20.0 \%)$. In the internal environments, the wet curtain cooling system (3/3) and egg nest samples (6/6) had the highest incidence of Salmonella (both $100 \%$ ), followed by cage samples $(5 / 6$, 83.3\%). Additionally, there were no significant differences between external $(71.4 \%, \mathrm{n}=30)$ and internal $(93.3 \%$, $\mathrm{n}=14)$ environment samples $(p=0.34, p>0.05)$.

Forty-four $(\mathrm{n}=69,63.8 \%)$ Salmonella isolates were recovered from the new layer farm (Table 2). The incidence of Salmonella in external environment of the new layer farm was $55.6 \%(30 / 54)$ and $93.3 \%(14 / 15)$ in internal environment. In external environment samples, washing water, irradiation room (UV) and feces had the highest incidence of Salmonella (all 100\%), followed by the package and storage rooms (both 33.3\%). The washing room had the lowest contamination of Salmonella $(2 / 12,16.7 \%)$. However, no significant difference was found between the external $(55.6 \%, \mathrm{n}=30)$ and internal $(93.3 \%, \mathrm{n}=14)$ environmental samples $(p=0.16$, $p>0.05)$.

\section{Distribution of different Salmonella serotypes in layer farm environment}

Serotypes detected among the 88 Salmonella isolated from environment of the two layer farms included $S$. Derby, $S$. Jerusalem, $S$. Bovismorbificans, $S$. Enteritidis, and unidentified serotypes. The most frequently observed Salmonella serovar was $S$. Derby $(67.0 \%, \mathrm{n}=59)$, followed by $S$. Jerusalem $(15.9 \%, \mathrm{n}=14), S$. Bovismorbificans $(8.0 \%, \mathrm{n}=7)$ and $S$. Enteritidis $(4.5 \%, \mathrm{n}=4)$. Four isolates could not be serotyped (4.5\%). Interestingly, $S$. Braenderup was only detected in egg samples, and there were no $S$. Enteritidis in egg samples.

As shown in Table 1, four Salmonella serotypes were present among 44. Salmonella isolates in the old layer farm. $S$. Derby was most frequently recovered serotype $(81.8 \%, \mathrm{n}=36)$, followed by $S$. Enteritidis and $S$. Jerusalem (both $6.8 \%, \mathrm{n}=3$ ), and $S$. Bovismorbificans $(2.3 \%$, $\mathrm{n}=1)$. $S$. Jerusalem was found in soil and fecal samples. Interestingly, $S$. Enteritidis was only present in the soil 
and $S$. Bovismorbificans was detected only in wet curtain system samples. One isolate with an unidentified serotype was recovered from a gutter sample.

Four Salmonella serotypes were also found in the new layer farm among the 44 Salmonella isolates, of which S. Derby was also the predominant serotype (52.3\%, $\mathrm{n}=23)$, followed by $S$. Jerusalem $(25.0 \%, \mathrm{n}=11), S$. Bovismorbificans $(13.6 \%, \mathrm{n}=6)$, and $S$. Enteritidis (2.3\%, $\mathrm{n}=1$ ), respectively. $S$. Derby was found in most samples but absent from irradiation room (UV) and storage room samples. $S$. Jerusalem was present in samples from the egg collection conveyer, washing room, washing water, irradiation room, storage room and feces. S. Bovismorbificans was detected in washing water and feces. Strangely, $S$. Enteritidis was only present in one fecal sample. Additionally, unidentified isolates were isolated from washing water, storage room and fecal samples.

\section{Frequency of Salmonella in egg production chain}

On the new layer farm, four points of the production chain were sampled (Table 3). Twenty-three of the 45 farm-level samples $(51.1 \%), 27.3 \%(n=6)$ at the processing level, 33.3\% $(\mathrm{n}=4)$ at the storage level and $50.0 \%(\mathrm{n}=6)$ at the retail level were positive for Salmonella contamination. Farm-level samples included those from cage, egg belt, egg (from belt), egg collection conveyer and egg (from conveyer), processing level included washing and irradiation room and package room samples, storage level included the storage room and retail level included retail eggs.

\section{PFGE typing}

To determine genetic similarity among isolates from different origins, we defined PFGE types as having similarity index equal to or greater than $75 \%$. Overall, a total of 15 distinct PFGE types were identified among the 111 Salmonella isolates (Additional file 2: Table S2, Additional file 3: Figure S1). Interestingly, isolates of PFGE type 1 were found in diverse samples including feces, dust, cage, egg nest, egg belt and washing room. Isolates 1 (dust), 2 (feces) from the external environment of the old layer farm had high similarity to isolate 3 (cage) and 4 (egg nest) of the internal environment of the old layer farm as well as to isolates 10,11, and 12 (cages) from the internal environment and isolates 13 and 14 (both from feces) from the external environment of the new layer farm. The same results were also found in isolate 34,35 and 36, 37 in different environment of the old layer farm. Additionally, the isolate 23 and 24, 44 and 45 of the old layer farm and 57 and 58, 68, 69 and 70 of the new layer farm in external environment also showed highly similarity to each other. There were also existed genetically relationship between isolates 6,7 and 8 from internal environment.

Table 3 Different level of the production chain of the two layer farms

\begin{tabular}{|c|c|c|c|c|c|c|c|c|c|}
\hline \multirow[t]{2}{*}{ Level } & \multirow[t]{2}{*}{ Origins } & \multirow[t]{2}{*}{$\mathrm{N}^{\mathrm{a}}$} & \multicolumn{6}{|c|}{ Salmonella serotypes } & \multirow[t]{2}{*}{ Prevalence $^{\mathbf{b}}$} \\
\hline & & & S. Derby & S. Braenderup & S. Enteritidis & S. Jerusalem & S. Bovismorbificans & Un-identified & \\
\hline \multicolumn{10}{|c|}{ Old layer farm } \\
\hline \multirow[t]{3}{*}{ Farm } & Cage & 6 & 5 & & & & & & $33.3 \%(18 / 54)$ \\
\hline & Egg (from cage) & 42 & 3 & & & 3 & & 1 & \\
\hline & Egg nest & 6 & 6 & & & & & & \\
\hline \multicolumn{10}{|c|}{ New layer farm } \\
\hline \multirow[t]{5}{*}{ Farm } & Cage & 6 & 6 & & & & & & $51.1 \%(23 / 45)$ \\
\hline & Egg belt & 6 & 6 & & & & & & \\
\hline & Egg (from belt) & 18 & 1 & 3 & & 1 & 1 & 1 & \\
\hline & $\begin{array}{l}\text { Egg collection } \\
\text { conveyer }\end{array}$ & 3 & 1 & & & 1 & & & \\
\hline & $\begin{array}{l}\text { Egg (from con- } \\
\text { veyer) }\end{array}$ & 12 & & & & 1 & 1 & 1 & \\
\hline \multirow{3}{*}{$\begin{array}{l}\text { Process- } \\
\text { ing }\end{array}$} & Washing room & 12 & 1 & & & 1 & & & $27.3 \%(6 / 22)$ \\
\hline & $\begin{array}{l}\text { Irradiation room } \\
\text { (UV) }\end{array}$ & 1 & & & & 1 & & & \\
\hline & Package room & 9 & 3 & & & & & & \\
\hline Storage & Storage room & 12 & & & & 3 & & 1 & $33.3 \%(4 / 12)$ \\
\hline Retail & Retail eggs & 12 & 1 & 1 & & 1 & & 3 & $50.0 \%(6 / 12)$ \\
\hline
\end{tabular}

a Sample number

${ }^{b}$ The prevalence of Salmonella was among the samples in different level of the production chain 
The isolates 6, 7 (from egg belt) of the new layer farm and 8 (from egg nest) of the old layer farm both in internal environment samples had been found a highly similarity to each other, respectively. Besides, the isolate 27, 28 (both from feces samples) of the new layer farm had also been found genetically related to the isolate 29 isolated from disinfection room samples of the old layer farm. The same results were also found between the isolates 57 (washing water), 58 (package room) of new layer farm and 59 (soil) of old layer farm as well as 75 (storage room) and 76 (feces), respectively. Indistinguishable $S$. Jerusalem isolates were also from different farms as were the $S$. Jerusalem isolates within type 5 . The same results were also found in $S$. Bovismorbificans in type 9 .

Additionally, the isolates from egg origins were also related to the Salmonella isolates from environment samples of the two layer farms. Two $S$. Braenderup isolates, one (94) isolated from the retail, another (95) from egg samples of belt, had a highly similarity of more than $85 \%$. The same results had also been found in four un-identified isolates (107 and 108, 110 and 111) with different origins.

\section{Discussion}

Human salmonellosis has been consistently associated with the consumption of poultry products worldwide [5, 27]. S. Derby was most frequently observed in layer farm environments while $S$. Jerusalem, $S$. Braenderup and $S$. Derby were the predominant serotypes in egg samples. Derby was one of the main serotypes in the present study, but only small outbreaks have been associated with this serotype according to the reports of the CDC website of USA. This finding may be attributable to the inherent physiological characteristics of Derby which lacks pathogenicity islands 13 and 14, the fimbrial lpf operon, and other regions that encode metabolic functions [28]. $S$. Jerusalem isolates from a chicken farm have also been reported previously [29]. Braenderup is reportedly a major cause of outbreaks in America [30]. Compared to environmental samples, the incidence of Salmonella was lower in egg samples, which was slightly lower $(16.7 \%$ in old layer farm) or consistent (33.3\%) with another report of Salmonella isolation from eggshells (34\%) [31]. In this study, Salmonella isolates were recovered not only from eggshells, but also from egg content. Previous studies revealed that under normal conditions of storage and moisture, Salmonella contaminating eggshells could migrate to the egg content [27], which might result in human infections.

Notably, the prevalence of Salmonella contamination in environment of the layer farm was somewhat higher than that in eggs in this and other studies [14, 27]. This prevalence was also higher compared with reported prevalence in live broiler chicken samples [14]. The environment of the layer farm was considered as a reservoir for Salmonella and could contribute to the horizontal/vertical dissemination of Salmonella [14, 32], since Salmonella had the ability to persist in both host and non-host environments for its enhanced survival capabilities [33].

Additionally, the incidence of Salmonella in the internal environment (93.3\%) was somewhat higher than in the external environment (55.6-77.2\%) of both layer farms. High similarities between these isolates were also found, which suggested that cage, egg belt and egg nest were the important reservoirs for Salmonella in the internal environments and that transmission of Salmonella occurs readily between locations in the internal environments. Furthermore, direct contact between egg belt and egg nest eggs were considered to be efficient mechanisms for the transmission of Salmonella [9, 11]. Although not assessed in this study, it is plausible that insects and mice play a role as vectors of Salmonella in internal environments of layer farms [34, 35]. Contaminated laying hens could spread Salmonella to nearby hens by direct contact or could disseminate Salmonella in egg forming by its reproductive tract [27]. Thus, these factors indicate complex network of potential cross-contamination of Salmonella in the internal environments of layer farms.

There also was high similarity among Salmonella isolates from the external environment. Feces, dust, water, and soil were the main source reservoirs for Salmonella in the external environments. Feces played an important role in Salmonella dissemination, as contaminated feces excreted into the environment could then be a source of the bacteria to naive hosts, perpetuating its survival over the layer farm environment $[9,11,14,32]$. Salmonella was also detected in rinsing water for egg washing. Contaminated washing water flowed along with the gutter and may be used for irrigation water, which could be a major route of Salmonella contamination for crops and produce [36, 37]. Dust has also been considered as a vector for Salmonella spread through potential airborne transmission [34]. Salmonella in dust could also contaminate pelleted feed [34, 38]. Contaminated soil could act as a persistent source of Salmonella difficult to disinfect [34, 37]. A moist floor associated with daily rinsing with water for cleaning and the spillage of water from the drinkers could provide favorable condition for survival of Salmonella [14].

The difference in prevalence of Salmonella in the external environment of the new layer farm to that of the old layer farm (55.6\% [30/54] versus $71.4 \%$ [30/42]) supports the use of newer farming technology as helpful for controlling Salmonella contamination. The lower frequency of Salmonella contamination in the disinfection system showed that disinfectant application and washing of eggs 
was contributing to preventing or reducing bacteria. To prevent Salmonella contamination in external environment, litter, feces and dust should be removed frequently and disinfectant applied to surfaces.

Salmonella isolates from internal and external environmental samples were also highly similar to each other. This might be explained by cross contamination between internal and external environments when birds or feces are removed [39]. Dust and waste drinking water also have the potential ability to spread Salmonella by airborne and waterborne transmission. Other vectors, such as mice, insects and wild birds could introduce Salmonella from external to internal environment [40, 41].

The prevalence of Salmonella changed dynamically along the egg production chain. The farm level had the highest prevalence of Salmonella, followed by retail level, storage and processing level. The reduced recovery of Salmonella at processing level might be owing to the strategies for prevention of egg contamination. Egg washing and disinfection were efficient ways to wash bacteria off of egg surfaces. Sealed packages also prevented contamination of eggs. However, during prolonged storage period, the risk of Salmonella contamination may increase and result in decreased quality of the egg products. Isolates from individual eggs were genetically similar to each other, which suggested that the Salmonella contamination of eggs at the farm level could persist into the retail level. Salmonella has been confirmed as having the capacity to colonize the reproductive tract of the laying hens and thereby contaminating forming eggs $[34,42,43]$. We found that isolates from different parts of the production chain were highly similar. Isolates from three different parts of the production chain (farm level, egg production processing part and retail level) had more than $85 \%$ similarity. The same results had also been found in isolates 94 (retail level) and 95 (farm level), 110 (retail level) and 111 (storage level). These results indicated that the pathogens could spread along with the poultry breeding to and production chain.

Cross-contamination between two layer farms was also evident from the PFGE results. The most probable explanation could be that breeder chickens upstream of the production chain contaminated both farms. The two layer farms had a same origin of layer chicks, which could introduce Salmonella [44]. Contaminated layer hens could transmit Salmonella to the forming egg within the reproductive tract [27], which may be the reason the two farms had the same frequency of Salmonella contamination (93.3\%) in internal environment. Another essential factor might owe to the exchange workers, equipment or managers between two layer farms. Humans and equipment as mechanical vectors could introduce Salmonella to each other indirectly $[34,39]$.
The findings presented herein indicated that there was a significant difference in contamination of Salmonella serotypes among egg samples and environmental samples. $S$. Enteritidis was absent in egg samples but present in environmental samples, which was different from previous studies $[14,18]$. In general, $S$. Enteritidis was confirmed as strongly associated with shell eggs and egg containing products [45]. The results might be due to strategies applied at the feeding and production processing line, such as disinfection, washing and UV radiation. Disinfection and UV radiation have the capacity to reduce or kill microorganisms on egg shell surfaces [34, $46,47]$. Egg washing was also used to reduce the bacterial contamination and to prevent penetration of bacteria to the egg contents [34]. Additionally, $S$. Braenderup was only present in egg samples, but not in environmental samples. Serotype-specific characteristics may explain their own niche preferences within poultry environments $[48,49]$.

This study showed that Salmonella contamination is common in the layer farms that we studied. $S$. Derby was most frequently observed in layer farm environments while $S$. Jerusalem, $S$. Braenderup and $S$. Derby were the predominant serotypes in egg samples. The prevalence of Salmonella in environment of the layer farm was higher than that in egg samples. The incidence of Salmonella in internal environment was relatively higher than in external environment in both layer farms. Salmonella could be disseminated not only between internal and external environment, but also between different layer farms. It could also spread along the egg production processing chain. Measures, such as cleaning and disinfection routinely etc., should be taken to prevent or reduce the dissemination of Salmonella in layer farm environment.

\section{Conclusions}

The findings indicated ongoing Salmonella cross-contamination inside or outside of the layer farms, and that Salmonella could also spread along the egg production line.

\section{Additional files}

Additional file 1: Table S1. The prevalence and distribution of Salmonella in egg samples.

Additional file 2: Table S2. PEGE type of Salmonella in different origins of the two layer farms.

Additional file 3: Figure S1. PFGE of Salmonella isolates from the two layer farms.

Abbreviation

PFGE: pulsed-field gel electrophoresis. 


\section{Authors' contributions}

AZ and $L Z$ conceived the idea. ML, YH, GW, SZ, WD, SC, KZ and SL performed the experiment. $L H, X A, M M$ and $M L$ conducted work in farms. YY, HW and BL performed statistical analyses. $M L$ and $L Z$ wrote the first draft of the manuscript, and MAD, LJ, HY, YY, ML and LZ contributed substantially to revisions. All authors read and approved the final manuscript.

\section{Author details}

${ }^{1}$ College of Resources, Sichuan Agricultural University, Chengdu 611130, People's Republic of China. ${ }^{2}$ Sichuan Entry-Exit Inspection and Quarantine Bureau, Chengdu 610041, People's Republic of China. ${ }^{3}$ National Quality Supervision and Inspection Center of Liquor Products (Sichuan), Yibin 644000, People's Republic of China. ${ }^{4}$ College of Food Science, Sichuan Agricultural University, Ya'an 625014, People's Republic of China. ${ }^{5}$ College of Life Sciences, Sichuan University, Chengdu 610065, People's Republic of China. ${ }^{6}$ College of Veterinary Medicine, Washington State University, Pullman, USA. ${ }^{7}$ Dujiangyan Campus, Sichuan Agricultural University, Chengdu 611830, People's Republic of China.

\section{Acknowledgements}

Not applicable.

\section{Competing interests}

The authors declare that they have no competing interests.

\section{Availability of data and materials}

All data and material will be available upon requests to the corresponding author.

\section{Consent for publication}

Not applicable.

\section{Ethics approval and consent to participate}

Not applicable.

\section{Funding}

This research was supported by the National Natural Science Foundation of China (31400066, 31671954), Science and Technology Department of Sichuan Province (2017JY0118)

\section{Publisher's Note}

Springer Nature remains neutral with regard to jurisdictional claims in published maps and institutional affiliations.

Received: 28 August 2017 Accepted: 5 December 2017

Published online: 14 December 2017

\section{References}

1. Scallan E, Hoekstra RM, Angulo FJ, Tauxe RV, Widdowson M, Roy SL, et al. Foodborne illness acquired in the United States-major pathogens. Emerg Infect Dis. 2011;17:7-15.

2. Grant A, Hashem F, Parveen S. Salmonella and Campylobacter: antimicrobial resistance and bacteriophage control in poultry. Food Microbiol. 2016;53:104-9.

3. EFSA. The European Union summary report on trends and sources of zoonoses, zoonotic agents and food-borne outbreaks in 2010. EFSA J. 2012;10:442.

4. Majowicz SE, Musto J, Scallan E, Angulo FJ, Kirk M, O'Brien SJ, International Collaboration on Enteric Disease 'Burden of Illness, $S$, et al. The global burden of nontyphoidal Salmonella gastroenteritis. Clin Infect Dis. 2010;50:882-9.

5. Zhao S, McDermott PF, Friedman S, Abbott J, Ayers S, Glenn A, et al. Antimicrobial resistance and genetic relatedness among Salmonella from retail foods of animal origin: NARMS retail meat surveillance. Foodborne Pathog Dis. 2006;3:106-17.
6. Messens W, Grijspeerdt K, De Reu K, De Ketelaere B, Mertens K, Bamelis F, et al. Eggshell penetration of various types of hens' eggs by Salmonella enterica serovar Enteritidis. J Food Prot. 2007;70:623-8.

7. Holt PS, Geden CJ, Moore RW, Gast RK. Isolation of Salmonella enterica serovar Enteritidis from houseflies (Musca domestica) found in rooms containing Salmonella serovar Enteritidis-challenged hens. Appl Environ Microbiol. 2007:73:6030-5.

8. Umali DV, Lapuz RR, Suzuki T, Shirota K, Katoh H. Transmission and shedding patterns of Salmonella in naturally infected captive wild roof rats (Rattus rattus) from a Salmonella-contaminated layer farm. Avian Dis. 2012:56:288-94.

9. McWhorter AR, Davos D, Chousalkar KK. Pathogenicity of Salmonella strains isolated from egg shells and the layer farm environment in australia. Appl Environ Microbiol. 2015;81:405-14.

10. Eriksson de Rezende CL, Mallinson E, Tablant NL, Morales R, Park A, Carr $L E$, Joseph SW. Effect of dry litter and airflow in reducing Salmonella and Escherichia coli populations in the broiler production environment. J Appl Poult Res. 2001;10:245-51.

11. Davies RH. Investigations into possible alternative decontamination methods for Salmonella Enteritidis on the surface of table eggs. J Vet Med B. 2003;50:38-41.

12. Maciorowski KGHP, Kundiger MM, Ricke SC. Animal feed production and contamination by foodborne Salmonella. J Verbrauch Lebensm. 2006;1:197-209.

13. Frederick A, Huda N. Salmonellas, poultry house environments and feeds: a review. J Anim Vet Adv. 2011;10:679-85.

14. Suresh T, Aam H, Harsha HT, Lakshmanaperumalsamy P. Prevalence and distribution of Salmonella serotypes in marketed broiler chickens and processing environment in Coimbatore City of southern India. Food Res Int. 2011;44:823-5.

15. McWhorter AR, Chousalkar KK. Comparative phenotypic and genotypic virulence of Salmonella strains isolated from Australian layer farms. Front Microbiol. 2015;6:12.

16. Yang B, Qiao L, Zhang X, Meng J. Serotyping, antimicrobial susceptibility, pulse field gel electrophoresis analysis of Salmonella isolates from retail foods in Henan Province, China. Food Control. 2013;32:228-35.

17. Manning J, Gole V, Chousalkar K. Screening for Salmonella in backyard chickens. Prev Vet Med. 2015:120:241-5.

18. Chousalkar KK, Flynn P, Sutherland M, Roberts JR, Cheetham BF. Recovery of Salmonella and Escherichia coli from commercial egg shells and effect of translucency on bacterial penetration in eggs. Int J Food Microbiol. 2010;142:207-13.

19. Deng X, Ran L, Wu S, Ke B, He D, Yang X, et al. Laboratory-based surveillance of non-typhoidal Salmonella infections in Guangdong Province, China. Foodborne Pathog Dis. 2012;9:305-12.

20. Center for Disease Control and Prevention (CDC). http://www.cdc.gov/ salmonella/index.html. 2014.

21. Yang B, Cui Y, Shi C, Wang J, Xia X, Xi M, et al. Counts, serotypes, and antimicrobial resistance of Salmonella isolates on retail raw poultry in the People's Republic of China. J Food Prot. 2014;77:894-902.

22. Kuang $X$, Hao H, Dai M, Wang Y, Ahmad I, Liu Z, et al. Serotypes and antimicrobial susceptibility of Salmonella spp. isolated from farm animals in China. Front Microbiol. 2015;6:602.

23. Shenghui $C$, Jiang Z, Jianghong M. An improved method for rapid isolation of Salmonella against Proteus in chicken carcasses. J Food Saf. 2006;26:49-61.

24. Gragg SE, Loneragan GH, Nightingale KK, Brichta-Harhay DM, Ruiz H, Elder JR, et al. Substantial within-animal diversity of Salmonella isolates from lymph nodes, feces, and hides of cattle at slaughter. Appl Environ Microbiol. 2013:79:4744-50.

25. Mohamed T, Zhao S, White DG, Parveen S. Molecular characterization of antibiotic resistant Salmonella Typhimurium and Salmonella Kentucky isolated from pre- and post-chill whole broilers carcasses. Food Microbiol. 2014;38:6-15.

26. Ribot EM, Fair MA, Gautom R, Cameron DN, Hunter SB, Swaminathan B, et al. Standardization of pulsed-field gel electrophoresis protocols for the subtyping of Escherichia coli 0157:H7, Salmonella, and Shigella for PulseNet. Foodborne Pathog Dis. 2006;3:59-67. 
27. Im MC, Jeong SJ, Kwon YK, Jeong OM, Kang MS, Lee YJ. Prevalence and characteristics of Salmonella spp. isolated from commercial layer farms in Korea. Poult Sci. 2015;94:1691-8.

28. Betancor L, Pereira M, Martinez A, Giossa G, Fookes M, Flores K, et al. Prevalence of Salmonella enterica in poultry and eggs in Uruguay during an epidemic due to Salmonella enterica serovar Enteritidis. J Clin Microbiol. 2010;48:2413-23.

29. Liljebjelke KA, Hofacre CL, Liu T, White DG, Ayers S, Young S, et al. Vertical and horizontal transmission of Salmonella within integrated broiler production system. Foodborne Pathog Dis. 2005;2:90-102.

30. Gupta SK, Nalluswami K, Snider C, Perch M, Balasegaram M, Burmeister D, et al. Outbreak of Salmonella braenderup infections associated with roma tomatoes, northeastern United States, 2004: A useful method for subtyping exposures in field investigations. Epidemiol Infect. 2007; 135:1165-73.

31. Garcia C, Soriano JM, Benitez V, Catala-Gregori P. Assessment of Salmonella spp. in feces, cloacal swabs, and eggs (eggshell and content separately) from a laying hen farm. Poult Sci. 2011;90:1581-5.

32. Singh R, Yadav AS, Tripathi V, Singh RP. Antimicrobial resistance profile of Salmonella present in poultry and poultry environment in north India. Food Control. 2013;33:545-8.

33. Condell O, Sheridan A, Power KA, Bonilla-Santiago R, Sergeant K, Renaut J, et al. Comparative proteomic analysis of Salmonella tolerance to the biocide active agent triclosan. J Proteom. 2012;75:4505-19.

34. Anca M, Galis CM, Didier M, Daniel P, Ilie V, Yves B, et al. Control of Salmonella contamination of shell eggs_-preharvest and postharvest methods: a review. Compr Rev Food Sci Food Saf. 2013:12:155-82.

35. Larsen MH, Dalmasso M, Ingmer H, Langsrud S, Malakauskas M, Mader A, et al. Persistence of foodborne pathogens and their control in primary and secondary food production chains. Food Control. 2014;44:92-109.

36. Levantesi C, Bonadonna L, Briancesco R, Grohmann E, Toze S, Tandoi V. Salmonella in surface and drinking water: occurrence and water-mediated transmission. Food Res Int. 2012;45:587-602.

37. Abakpa GO, Umoh VJ, Ameh JB, Sijam K. Diversity and antimicrobial resistance of Salmonella enterica isolated from fresh produce and environmental samples. Environ Nanotechnol Monit Manag. 2015;3:38-46.

38. Jones FT, Richardson KE. Salmonella in commercially manufactured feeds. Poult Sci. 2004;83:384-91.
39. Cardinale E, Tall F, Gueye EF, Cisse M, Salvat G. Risk factors for Salmonella enterica subsp. enterica infection in senegalese broiler-chicken flocks. Prev Vet Med. 2004;63:151-61.

40. Yang X, Bullard BR, Geornaras I, Hu S, Woerner DR, Delmore RJ, et al. Comparison of the efficacy of a sulfuric acid-sodium sulfate blend and lactic acid for the reduction of Salmonella on prerigor beef carcass surface tissue. J Food Prot. 2017:3:809-13.

41. Mian LS, Maag H, Tacal JV. Isolation of Salmonella from muscoid flies at commercial animal establishments in San Bernardino County, California. J Vector Ecol. 2002;27:82-5.

42. Wales AD, Davies RH. A critical review of Salmonella Typhimurium infection in laying hens. Avian Pathol. 2011;40:429-36.

43. Martelli F, Davies RH. Salmonella serovars isolated from table eggs: an overview. Food Res Int. 2012;45:745-54.

44. Dorea FC, Cole DJ, Hofacre C, Zamperini K, Mathis D, Doyle MP, et al. Effect of Salmonella vaccination of breeder chickens on contamination of broiler chicken carcasses in integrated poultry operations. Appl Environ Microbiol. 2010;76:7820-5.

45. Howard ZR, O'Bryan CA, Crandall PG, Ricke SC. Salmonella Enteritidis in shell eggs: current issues and prospects for control. Food Res Int. 2012;45:755-64.

46. Suzuki Y, Hanagasaki N, Furukawa T, Yoshida T. Removal of bacteria from coastal seawater by foam separation using dispersed bubbles and surface-active substances. J Biosci Bioeng. 2008;105(4):383-8.

47. Møretrø T, Heir E, Nesse LL, Vestby LK, Langsrud S. Control of Salmonella in food related environments by chemical disinfection. Food Res Int. 2012:45:532-44.

48. Gast RK, Guraya R, Guard-Bouldin J, Holt PS, Moore RW. Colonization of specific regions of the reproductive tract and deposition at different locations inside eggs laid by hens infected with Salmonella Enteritidis or Salmonella Heidelberg. Avian Dis. 2007;51:40-4.

49. Gantois I, Eeckhaut V, Pasmans F, Haesebrouck F, Ducatelle R, Van Immerseel F. A comparative study on the pathogenesis of egg contamination by different serotypes of Salmonella. Avian Pathol. 2008;37:399-406.

\section{Submit your next manuscript to BioMed Central and we will help you at every step:}

- We accept pre-submission inquiries

- Our selector tool helps you to find the most relevant journal

- We provide round the clock customer support

- Convenient online submission

- Thorough peer review

- Inclusion in PubMed and all major indexing services

- Maximum visibility for your research

Submit your manuscript at www.biomedcentral.com/submit
BioMed Central 